\title{
Modernização e desenvolvimento político: duas visões sobre o pacote democracia-capitalismo
}

Paulo Sergio Peres

\section{Resumo}

A possível relação entre regime político e desenvolvimento sócio-econômico tem sido um dos principais temas da análise de política comparada desde os anos de 1960. É possível identificar na literatura dois tipos de resposta a esse problema. Uma, ligada às formulações de Huntington, enfatizou as diferenças culturais de cada país, salientando que em alguns deles não havia uma cultura favorável ao desenvolvimento democrático. A outra, ligada à teoria de Lipset, destacou variáveis sociológicas, argumentando que a estrutura sócio-econômica tradicional impedia a efetividade democrática. Meu objetivo neste texto é analisar as formulações básicas de cada um desses autores a respeito do tema, procurando discutir a validade dos seus argumentos centrais. Conforme procurarei argumentar, as hipóteses por eles apresentadas continuam a entreter analistas $e$ a provocar refutações $e$ revitalizações de suas inferências, em um debate teórico, conceitual e metodológico que ainda não está de todo concluído.

Existe alguma relação entre regime político e desenvolvimento sócio-econômico? Caso exista, essa relação seria positiva ou negativa? Haveria variações nessa relação em função do tipo de regime político, se democracia ou autoritarismo? Caso haja, como esta seria? Tais questões têm estado no centro das indagações de sociólogos e cientistas políticos desde a pós-Segunda Guerra. A descolonização dos países 
africanos, a atenção redobrada com a América Latina e a reconstrução econômica e política da Europa estimularam a proliferação de análises de política comparada. O ponto central era: por que a mera instalação da democracia liberal, com eleições livres e competitivas, não produzia os mesmos efeitos observados em democracias mais antigas, como a norte-americana? Especialmente na América Latina, região constantemente ameaçada por instabilidades institucionais e "solução pretoriana"? Houve dois tipos de resposta. Uma enfatizou as diferenças culturais de cada país, salientando que em alguns deles não havia uma cultura favorável ao desenvolvimento democrático. Outra, destacou variáveis sociológicas, argumentando que a estrutura sócio-econômica tradicional impedia a efetividade democrática.

De certa forma, ambas as respostas se voltaram para um dos eixos fundamentais da democracia: a participação política. Um dos requisitos para a legitimidade e até para o funcionamento da democracia representativa é a ampliação da participação política por meio de eleições. Segundo vários analistas, isso impunha o clássico dilema já enfrentado décadas antes por parte dos países da Europa e pelos Estados Unidos, que era o da participação das massas, de sua introdução no sistema político. Ainda segundo esses analistas, os países latinoamericanos, cuja estrutura sócio-econômica apresentava fortes características de sociedades tradicionais, com pouca diferenciação entre as esferas sociais e com pouco apego à formalidade dos procedimentos de uma sociedade moderna, teriam de enfrentar esse problema como um inevitável processo de duplo desenvolvimento: sócio-econômico e político.

Contudo, a natureza da relação entre essas duas variáveis foi fonte de grande controvérsia - e, de alguma forma, ainda o é. É possível identificar pelo menos duas visões divergentes a respeito do tipo de impacto que a modernização sócio-econômica causaria no desenvolvimento político. Ambas as visões pertencem a autores importantes e credenciados representantes de um tipo de linha de pesquisa que se estruturou em torno das hipóteses e dos postulados por eles formulados. Esses autores são Lipset $(1959,1967)$ e Huntington $(1975)$, dois dos principais formuladores da conjectura do desenvolvimento político.

Meu objetivo neste texto é analisar as formulações básicas de cada um desses autores a respeito do tema, procurando demarcar pon- 
tos de convergência e pontos de distanciamento. Além disso, procurarei discutir a validade dos seus argumentos centrais. Para tal finalidade, serão utilizadas como contraponto análises de alguns autores que colocaram sob o crivo do teste empírico as deduções lógicas e factuais extraídas das formulações de cada um daqueles autores. Ficará evidente que as hipóteses apresentadas, ainda em meados dos anos 60, continuam a entreter analistas e a provocar refutações e revitalizações de suas inferências, em um debate teórico, conceitual e metodológico que ainda não está de todo concluído.

\section{A conjectura do desenvolvimento político}

Os estudos comparativos que enfocaram o problema do desenvolvimento político, grosso modo, dividem-se em duas vertentes analíticas, cada uma delas com suas investigações voltadas a um conjunto específico de variáveis, consideradas como sendo as mais relevantes para explicar as variações políticas e o desempenho das instituições democráticas em cada país. Esses conjuntos de variáveis são relativos à cultura política e à estrutura sócio-econômica.

As análises de cultura política tinham como base concepções sociológicas e psicológicas a respeito do que consideravam determinante no comportamento dos indivíduos e, como tal, na interiorização dos valores necessários à legitimação do procedimento democrático, que eram os processos de socialização dos atores políticos pelos grupos primários. De certa forma, essa cultura, uma vez formada, quase sempre na infância, muito dificilmente sofreria alterações. Em se tratando do conjunto da sociedade, suas predisposições básicas, no agregado, também dificilmente se modificariam em curto e médio prazos. Para que isso ocorresse, seriam necessárias sucessivas gerações submetidas a outros processos de socialização. A mudança desses processos de socialização, por sua vez, estaria associada a mudanças estruturais da sociedade, implicando na passagem de formas de sociabilidade e de socialização de moldes tradicionais para outra, de moldes modernos.

Muito provavelmente, a melhor definição desse tipo de análise foi dada por Eckstein (1988, 290-1). A citação é longa, mas muito esclarecedora. Segundo ele 
"the touchstone of culturalist theory is the postulate of oriented action: actors do not respond directly to situations but respond to them through mediating orientations. (...) Orientations to action are general dispositions of actors to act in certain ways in sets of situations. Such general dispositions pattern actions. If actors do not have them, or if orientations are ill formed or inconsistent, actions will be erratic: patternless, anomic. The idea of orientations to action follows a particular psychological stimulus-response model: (...) mediational models in which responses to stimuli (actions in situations are considered results both of the experience of objective situations and actors' subjective processing of experience). Orientations do the processing. (...) Orientations are not attitudes: the later are specific, the former general, dispositions. Attitudes themselves derive from and express orientations; though attitudes may, through their patterning, help us to find orientations. If orientations frequently occur in collectivities they may be called culture themes (...). These themes exemplify how orientations are general dispositions that pattern sets of actions and sets of specific attitudes. It is conventional to regard orientations as having three components: cognitive elements that decode experience (give it meaning); affective elements that invest cognition with feelings that move actors to act; and evaluative elements that provide objectives toward which actors are moved to act."

As análises centradas em variáveis sócio-econômicas, por outro lado, apresentam características mais nitidamente sociológicas, utilizando, geral mas não exclusivamente, os conceitos e a concepção teórica do estrutural-funcionalismo. De maneira genérica, a lógica de sua explicação se concentra na pressuposição de que os indivíduos sofreriam pressões sociais cruzadas de maneira constante, sendo, assim, permanentemente socializados e sujeitos a mudanças. Porém, estas, como no caso da vertente culturalista, também estariam associadas a mudanças de natureza estrutural. O que mais interessa aos sociólogos estruturalistas são as relações de conflito entre as classes sociais, as relações entre classes ou grupos e o Estado, as representações partidárias assentadas em clivagens sociais, geralmente de classe, a fragmentação dos interesses de classe com a conseqüente pluralização da sociedade, o processo de aumento da complexidade social e suas conseqüências políticas, etc. 
Como podemos perceber, é possível deduzir que, do ponto de vista normativo, as reformas que deveriam ser derivadas dessas concepções gerais acerca da organização e da dinâmica da sociedade seriam convergentes, uma vez que tanto a cultura política quanto os aspectos sociais teriam como ponto inicial de mutação alterações estruturais na esfera econômica. Em sendo alterações rumo à estruturação capitalista, teríamos os seguintes fatores como efeito secundário desse processo: urbanização, aumento no nível do bem-estar da população, maior acesso a informações, maior possibilidade de organização dos interesses e a composição de classes sociais. Quanto à composição do antagonismo de classe, isso ocorreria apenas em um primeiro momento, pois, ao longo do processo, essas classes seriam cada vez mais fragmentadas e a sociedade deveria passar a ser pluralista.

Portanto, mudanças de uma cultura política paroquial ou alienada, implicariam, primeiramente, em transformações econômicas, estruturais, que causariam esse impacto positivo na sociedade, levando-a ao estágio de uma cultura política cívica e, conseqüentemente, democrática (cf. Almond \& Powell Jr.: 1980). Da mesma forma, mudanças estruturais da sociedade, que conduzam a sua pluralidade, deveriam, antes, no caso de sociedades tradicionais, promover sua modernização em estágios, necessários, fazendo surgir primeiramente os antagonismos de classe e, posteriormente, sua fragmentação (Lipset: 1959, 1967).

Apesar da diferenciação quanto à perspectiva metodológica, é patente que vários analistas mostraram-se permeáveis ao entrecruzamento dessas duas vertentes. Analistas que priorizaram variáveis estruturais também se preocuparam com a cultura política de dada sociedade $e$ a introduziram de maneira relevante em seus estudos. Analistas que privilegiaram a cultura política, da mesma maneira, mostraram-se atentos às variáveis sociais e econômicas, uma vez que, em sua concepção, alterações estruturais desencadeariam, em processos seculares, mudanças culturais nas sociedades.

Contudo, se a perspectiva do que causaria mudanças no comportamento político dos atores, seja alterando sua cultura, seja mudando suas formas de sociabilidade, é convergente em ambas as vertentes, o conteúdo dessas mudanças é ponto de divergência entre alguns autores. Esse é o caso de Lipset $(1959,1967)$ e Huntington (1959), que concordam quanto ao primeiro aspecto, mas divergem quanto ao segundo. Para Lipset $(1959,1967)$, a modernização sócio-econômica 
e o desenvolvimento político comporiam um pacote positivo, no qual a modernização estaria associada à produção de maior estabilidade política, dinamizando a democracia. Para Huntington (1959), de maneira inversa, ambas as variáveis comporiam um pacote negativo, em que modernização sócio-econômica geraria crescente instabilidade institucional, produzindo violência política; ou seja, produzindo a "quebra" da democracia.

A maneira como cada qual apresenta sua argumentação não provoca, entretanto, divergências quanto à vertente analítica, o que significa que esses autores concebem as variáveis culturais como fundamentais. O mecanismo explicativo dessa interação, que é estabelecido em suas análises, baseia-se na concepção de que a democracia terá maior estabilidade e, assim, maior longevidade, quando a esfera política for institucionalizada. Isso quer dizer duas coisas: quando as regras do procedimento democrático forem internalizadas, o que se traduz em legitimidade, e quando a política se constituir de forma autônoma em relação aos outros subsistemas sociais. Essa articulação ocorreria como um processo sociológico, demandando para tanto, diferenciação social suficiente a ponto de a política ser um subsistema autônomo $e$ de os atores a perceberem como tal, e a conceberem suas prerrogativas como válidas e legítimas. A democracia, assim, seria uma instituição, ou seja, um procedimento recorrente e, acima de tudo, um valor compartilhado. A diferenciação social, que traria alterações culturais em favor de maior civismo, compõe o pacote da modernização, ${ }^{1}$ desencadeado por transformações estruturais da economia.

Apesar dessa convergência analítica, Lipset $(1959,1967)$ e Huntington (1959) se colocam em lados relativamente opostos quanto aos

1 Este conceito já foi discutido por vários autores, que, por vezes, apresentam discrepâncias. Contudo, de forma geral, é possível apreender um conjunto mínimo e consensual de características que o configuram. Przeworski e Limongi $(1997,158)$ apresentam algo desse tipo, definindo-a desta forma: "modernization consists of a gradual differentiation and specialization of social structures that culminates in a separation of political structures from other and wakes democracy possible. The specific causal chains consist of sequences of industrialization, urbanization, education, communication, mobilization, and political incorporation, among innumerable others: a progressive accumulation of social changes that ready a society to proceed to its culmination, democratization". De forma geral, os autores sintetizam as definições apresentadas por Lipset $(1959,1967)$ e Huntington (1975). 
efeitos que a modernização produziria - por exemplo, em sociedades latino-americanas. A análise de Lipset $(1959,1967)$ subsidiaria um tipo de política de reformas cujo teor básico seria o incentivo à transformação econômica dessas sociedades rumo ao capitalismo ou à modernização. Huntington (1959), por ter a convicção de que no processo de modernização a cultura política não se alteraria tão rapidamente como a economia, compõe um argumento oposto. ${ }^{2}$ Nos próximos tópicos, serão discutidas mais detalhadamente as argumentações de cada autor, confrontadas com algumas análises empíricas de suas principais hipóteses.

\section{Lipset: a modernização como um pacote positivo}

O artigo no qual Lipset (1959) estabelece sua hipótese de relação positiva entre desenvolvimento sócio-econômico e estabilidade da democracia - onde ela já existia ou possibilidade elevada de seu surgimento onde exista autoritarismo -, já é considerado um clássico sobre o tema do desenvolvimento político, e isso por várias razões. ${ }^{3}$ Mas, do que trata especificamente esse artigo de Lipset (1959)? Qual seu problema central? Qual sua hipótese? Como é apresentado o mecanismo explicativo que articula as variáveis contidas na hipótese principal?

De acordo com a argumentação de Lipset (1959), o problema fundamental de uma democracia é sua manutenção. Esse é o problema central da abordagem sociológica que o autor faz da democracia enquanto um fenômeno político. A partir disso, a questão por ele trabalhada é referente às condições estruturais necessárias ao surgimento e à manutenção do regime democrático. Embora o autor conceba a

2 A menos, é claro, que se façam reformas políticas em primeiro lugar, reformas estas que criassem mecanismos de controle da participação político-eleitoral das massas e contenção de seu conflito.

3 Burkhart \& Lewis-Beck (1994, 903), por exemplo, enfatizam que apesar de não haver muitas leis sociológicas, a hipótese de Lipset (1959) tem sido tratada como se fosse uma delas, uma vez que sua "(...) central hypothesys seem so established as to be almost beyond challenge. (...) The notion of economic development as a requisite to democracy has survived increasingly sophisticated statistical tests". Além disso, segundo Diamond (1992), esse texto de Lipset (1959) é um dos mais citados em Sociologia Política e em Ciência Política. 
democracia como um procedimento e saliente a importância relativa das instituições políticas ou do desenho institucional, sua ênfase é colocada sobre os aspectos sócio-econômicos do fenômeno. A partir disso, Lipset (1959) estabelece a hipótese de que condições estruturais estariam associadas à democracia, ao seu surgimento, a sua existência e a sua estabilidade. O desenvolvimento do mecanismo explicativo da interação desses dois conjuntos de variáveis tem como ponto de partida uma dupla abordagem: a morfologia social e as atitudes e crenças dos atores. Assim, o autor realiza uma análise sociológica de orientação comportamentalista. ${ }^{4}$

A especificação de sua hipótese em termos sociológicos o conduz à conjectura de que o sistema político seria sustentado por condições ou variáveis exógenas. Nesse caso, a democracia seria apoiada por uma cultura política favorável aos seus procedimentos e por uma estrutura sócio-econômica moderna. Conforme sugerem Burkhart \& Lewis-Beck (1994, 903), "among the many reasons offered for this empirical connection, a common idea is that increasing economic benefits for the masses intensity demands for the political benefits of democracy".

Desse modo, emergem dois pontos básicos de toda sua discussão. O primeiro é a abordagem das supostas condições propícias ao surgimento da democracia, conduzindo o autor a demonstrações históricas e estatísticas - neste último caso, apoiado em dados referentes à estrutura sócio-econômica de vários países, com indicadores como industrialização, riqueza, urbanização e educação. O segundo é a verificação das supostas condições de longevidade das democracias já existentes ou instaladas, o que remete o foco analítico do autor aos tipos de instituições sociais e aos valores existentes em cada sociedade investigada. "These (are) presented as structural characteristics of a society which sustains a democratic political system" (Lipset: 1959, 71). Há uma questão fundamental com relação a esse segundo ponto. As características estruturais analisadas pelo autor se referem fundamentalmente às clivagens sociais, seu processo de constituição. A hipótese secundária que está subjacente à argumentação é a de que uma estru-

4 Conforme ressalta Lipset $(1959,69)$, "The condition associated with the existence and stability of democratic society have been a leading concern of political philosophy. In this work the problem is attacked from a sociological and behavioral standpoint". 
turação de clivagens de maneira pluralista (fragmentação das classes) ajudaria no empowerment da democracia.

A partir desse raciocínio, teríamos uma questão de natureza político-institucional que se remete ao centro dessa lógica e se impõe quase que de forma dedutiva, mas que é totalmente descartada pelo autor. O postulado da pluralização das clivagens sociais como fator de fortalecimento da democracia impõe, como corolário possível, a dedução de que um sistema multipartidário anularia esse efeito de "diversificação" do mercado de demandas sociais, na medida em que construiria múltiplos pólos de tensão. Dessa forma, um sistema bipartidário atuaria com a função de agregar preferências, de integrar interesses diferenciados, moderando as tensões. Por outro lado, um sistema bipartidário com uma estrutura de classes clássica, dicotômica, seria um incentivo à transposição do conflito, de maneira radical, à esfera política.

Assim, embora o autor não enfatize os aspectos institucionais do desenvolvimento político, é possível deduzir que a pluralização da sociedade levaria à moderação na medida em que os novos conflitos, fragmentados, fossem articulados por um sistema de representação majoritária. A despeito disso, Lipset $(1959,98)$ salienta: "clearly, stable democracies are compatible with multiparty system with proportional representation, and with a unitary state. And in fact, I would argue that such variations in systems of government, while significant, are much less important than those derived from basic differences in social structure (...)". Não se trata aqui de pontuar seu suposto equívoco quanto aos esperados efeitos de radicalização política produzidos pela representação proporcional, aos quais se dedicaram tanto Huntington (1975) quanto, mais diretamente, Sartori $(1968,1982)$; trata-se de sublinhar a primazia das estruturas sociais na sua análise e o deslocamento das instituições políticas a um segundo plano.

O procedimento de colocar as instituições sociais no centro da análise, remetendo as instituições do sistema político à periferia do problema investigado foi uma das principais características da abordagem de Lipset $(1959,1967)$ acerca do processo de desenvolvimento político. Quanto a esse aspecto, o próprio autor explicita a natureza de sua pressuposição teórica, afirmando que "perhaps the most widespread generalization linking political systems to other aspects of society has been that democracy is related to the state of economic developments. 
Concretely, this means that the more well-to-do a nation, the greater chances that it will sustain democracy" (ibid., 75).

Portanto, fica claro que a preocupação central de Lipset (1959, 1967) é discutir os requisitos estruturais para o surgimento e a longevidade da democracia. Esses requisitos estruturais são referentes às características sociológicas derivadas do processo de modernização da sociedade, o que inclui, de forma geral, pluralização de sua estrutura de clivagens e a conseqüente mudança da cultura política. Dessa maneira é que o autor sugere a relação de associação positiva entre democracia e desenvolvimento sócio-econômico.

\section{Huntington: a modernização como um pacote}

Assim como Lipset $(1959,1967)$, Huntington (1975) é um digno representante do grupo de analistas que se dedicam ao tema da democracia, mais especificamente do desenvolvimento político. Isso, na verdade, fez parte, desde o início, de um programa de pesquisa com finalidades aplicadas, que tinha como objetivo a proliferação do modelo democrático liberal por diversos países (Chilcote: 1998). A América Latina, considerada uma região cronicamente autoritária, impunha o problema de teimar em ser destoante em relação ao modelo. Os resultados produzidos pela democracia não chegavam perto daqueles esperados. Dessa forma, um segundo objetivo prático daquele programa de pesquisa era apresentar as causas dessa dissonância, com o propósito de superá-las.

Como vimos anteriormente, Lipset $(1959,1967)$ enfatizou causas estruturais e propôs um pacote positivo entre modernização (sócioeconômica) e desenvolvimento político (democracia). Huntington (1975) inverteu o sinal da equação, apresentando justamente uma relação inversa. Mas, afinal, quais são as principais contribuições do autor à questão do desenvolvimento político? Quais são as críticas apresentadas ao "pacote" positivo de Lipset $(1959,1967)$ ? Quais as pressuposições que subsidiam sua perspectiva negativa quanto à interação modernização/ desenvolvimento político?

É possível assinalar que a maior contribuição de Huntington (1975) ao debate sobre os condicionantes do desenvolvimento político 
ocorreu de duas formas. Primeiro, o autor contribui por ter introduzido variáveis político-institucionais no centro da discussão, ao propor um tipo de solução institucional para o problema da participação política, que, de acordo com sua argumentação, deveria ser de forma controlada. A segunda contribuição o coloca em confronto direto com as proposições de Lipset $(1959,1967)$, ao estabelecer que não haveria nenhum princípio de causalidade mecânica entre modernização $e$ desenvolvimento político. Pelo menos de forma positiva. Na verdade, segundo sua argumentação, se há alguma relação, esta é probabilística e ocorreria de forma negativa. ${ }^{5}$ Ou seja, a relação possível entre modernização e democracia é que a primeira, enquanto um processo sociológico, geraria instabilidade política e, como tal, possibilidade de "quebra" da democracia.

Em relação ao primeiro ponto, à introdução das instituições políticas no centro da questão, Remmer $(1997,51)$ aponta que “(...) such approaches make it possible to conceptualize political democracy less as the product of a particular set of cultural traditions, historical pattern of development, or level of modernization than as a consensual framework or cooperative equilibrium that may be constructed in a variety of ways, involve varying sets of rules or institutional arrangements, and yield disparate sets of political outcomes". Embora seja correta a avaliação do autor a respeito da perspectiva analítica voltada aos resultados políticos condicionados pela estrutura institucional, este não percebeu devidamente a função das instituições no modelo huntingtoniano.

No caso de Huntington (1975), a valorização de variáveis institucionais não implicou em desconsiderar a cultura ou o grau de modernização da sociedade, implicou, na verdade, em oferecer uma solução institucional para um problema cuja natureza era essencialmente cultural, potencializada pelo processo de modernização. Sobre isso, o autor

5 A relação seria probabilística porque não seria mecânica, determinista; e o seria devido à possibilidade de sua contenção ou de seu controle por meios institucionais. Huntington (1975) sugere um rígido controle do processo de participação política eleitoral, com o incentivo à partidos fortes, o que significa partidos de massa, e a um sistema majoritário. Além disto, a relação também é probabilística em termos empíricos, uma vez que o autor baseia sua argumentação em dados de uma pesquisa que apontou uma correlação positiva entre modernização $e$ instabilidade política (ibid., 52-66). 
afirma: "as instituições políticas possuem dimensões morais e estruturais. Uma sociedade com instituições políticas débeis não tem capacidade para dominar os excessos de desejos pessoais e paroquiais. A política é um mundo hobbesiano de implacável competição entre forças sociais (...), uma competição não mediada por organizações políticas mais amplas. (...) Sem instituições políticas fortes, a sociedade carece dos meios para definir e realizar seus interesses comuns" (Huntington: 1975, 36).

Justamente por conceber as instituições políticas como algo que teria a função de moldar os comportamentos e de limitar o radicalismo entre grupos ou facções é que estas aparecem em relevo em sua análise, mas, por outro lado, sem minimizar a importância das variáveis culturais e estruturais, ou colocá-las em segundo plano. As instituições ocupam, portanto, um lugar central em sua argumentação; porém, com uma perspectiva prescritiva. Essa perspectiva apresenta duas dimensões: instituições enquanto processo sociológico - e como tal, enquanto processo de institucionalização, ou seja, de interiorização de normas por um sistema de incentivos e punições - e enquanto processo de diferenciação entre os subsistemas sociais.

Dessa forma, o desenvolvimento político seria configurado pela diferenciação e pela autonomia da esfera política em relação às outras esferas da vida social, por um lado, e, por outro, pela legitimidade conferida aos procedimentos impostos pelo sistema, o que se traduziria em padrões de comportamento recorrentes. Esse duplo processo produziria, como resultado sociológico, a moralidade pública adequada à estabilidade política. O mecanismo causal apresentado pelo autor é o seguinte: "a moralidade requer confiança; a confiança envolve previsibilidade; $e$ a previsibilidade requer padrões de comportamento regularizados e institucionalizados" (ibid.). Essas, portanto, seriam as funções que as instituições deveriam cumprir no ordenamento social, sendo esse também o lugar que elas ocupam em seu modelo analítico.

Quanto à segunda contribuição, esta nos leva à visão crítica que Huntington (1975) apresentava em relação à associação entre modernização e desenvolvimento político. Segundo o autor, a modernização seria um processo multifacetado, envolvendo uma série de transformações econômicas, psicológicas, sociais e políticas. Geralmente, esses processos são vistos como concomitantes, a ponto de comporem um pacote tão amarrado que, muitas vezes, essas dimensões não são vis- 
tas como independentes. "Contudo, é um erro concluir que, na prática, a modernização implica a racionalização da autoridade, a diferenciação da estrutura e a expansão da participação. (...) Na prática, a modernização sempre envolve mudança e, usualmente, a desintegração de um sistema político tradicional, mas não envolve necessariamente um movimento significativo em direção a um sistema político moderno. (...) A modernização social, até certo grau, é um fato na Ásia, África e América Latina, a urbanização é rápida, o analfabetismo aos poucos vai sendo erradicado, a industrialização está sendo estimulada, o produto nacional bruto per capita está se elevando, expandemse os veículos de comunicação de massa. Em contraste, o progresso em direção a muitos dos outros objetivos que os escritores costumam identificar com a modernização política - democracia, estabilidade, diferenciação estrutural, padrões de desempenho, integração nacional - é freqüentemente, na melhor das hipóteses, incerto" (ibid., 48).

Com isso, Huntington (1975) procurou fundamentar sua "hipótese do hiato", pela qual era caracterizada a complexa situação da passagem da sociedade tradicional para a moderna, momento em que "os novos valores solapam as velhas bases de associação e de autoridade, antes que novas faculdades, motivações e recursos possam surgir para criar novos agrupamentos" (ibid., 49). O mecanismo causal apresentado pelo autor estabelece que a nova situação imporia novas experiências e estas "(...) rompe(riam) as barreiras cognitivas e atitudinais da cultura tradicional e promove(riam) novos padrões de aspirações $e$ anseios" (ibid., 67). Contudo, continua o autor, "a capacidade de uma sociedade em transição satisfazer essas novas aspirações aumenta em um ritmo muito mais lento que as aspirações em si. Conseqüentemente, desenvolve-se um hiato entre aspirações e expectativas, entre a formação do anseio e a sua satisfação, entre a função das aspirações e a função do nível de vida real" (ibid.). Assim, "na prática, a extensão do hiato proporciona uma medida razoável da instabilidade política" (ibid.)

Nesse caso, é importante salientar que o autor mostra-se mais preocupado com a estabilidade política do que com a implantação de um regime específico, ou seja, a democracia. Substituindo democracia por estabilidade política como questão central de reflexão, o autor salienta que, independentemente do regime político em vigência em determinado país, o importante é assegurar-lhe estabilidade, controlando 
os elementos que produziriam sua desestabilização. Dessa forma, o importante seria a coesão social. Esta seria desintegrada no interregno entre a sociedade tradicional e a sociedade moderna. O problema, portanto, residiria na passagem do tradicional ao moderno, no processo, na transição, na modernização. As mudanças gerariam uma exasperação das expectativas por mais bens públicos, causando uma explosão de demandas. As alterações sociais e psicológicas ocorreriam com maior rapidez em comparação com as mudanças do sistema político. Assim, a explosão de demandas sobre um sistema político ainda inapto a respondê-las, produziria uma crescente instabilidade política, que seria cada vez maior em correlação com a própria modernização. Quanto a isso, há duas componentes fundamentais no processo de crescente instabilidade política. A primeira seria a abertura de canais de participação política das massas. A segunda seria as instituições encarregadas de mediar essa participação. Esse é um ponto fundamental no contexto da argumentação huntingtoniana. Segundo o autor (ibid., 68), "o atraso político do país, em termos de institucionalização política, torna difícil, quando não impossível, que as demandas ao governo se expressem através dos canais legítimos e sejam moderadas e integradas no sistema político. É por isso que o aumento acentuado da participação política redunda em instabilidade política".

Dessa maneira, temos que o mecanismo causal entre modernização e instabilidade política é dado pela crescente mobilização social para a participação eleitoral em um contexto de explosão de demandas, no qual o sistema político se insere de forma frágil, pois, os partidos políticos, pouco institucionalizados, não cumprem sua função de "filtro" de tais demandas e não integram as diversas expectativas, moderando e controlando a participação. Pelo contrário, atuam como "tradutores" dessas demandas, deslocando conflitos sociais para a esfera política, produzindo violência e instabilidade. É com tal perspectiva que Huntington (1975) apresenta uma argumentação oposta à de Lipset (1959, 1967), subsidiando a visão de que investimentos orientados à promoção do capitalismo em países como a América Latina, ao invés de induzir à instauração ou à longevidade da democracia, deveria provocar uma crescente instabilidade política.

O problema central desse tipo de argumento é que, admitindo que países já modernos seriam estáveis, em sendo democráticos, teriam democracias estáveis, e que países em modernização enfrenta- 
riam instabilidade política, somos levados a deduzir que a transição mais segura entre os dois tipos de sociedade deveria ser conduzida por um sistema político forte, ou seja, um governo autoritário mesmo. Se Huntington (1975) foi extremamente perspicaz ao criticar o mecanicismo do pacote positivo de Lipset $(1959,1967)$, em contrapartida, ficou preso na mesma armadilha ao apresentar seu pacote negativo, qual seja, a da inescapável herança cultural da sociedade - embora tenha apresentado a ressalva da importância do desenho institucional tanto para a estabilidade política quanto para a vigência da democracia.

\section{Abrindo os pacotes de Lipset e Huntington}

As conjecturas apresentadas por Lipset $(1959,1967)$ e Huntington (1975) estabelecem duas possibilidades de relação de associação entre as variáveis modernização e desenvolvimento político, configurando duas hipóteses concorrentes. Para Lipset (1959, 1967), a relação é positiva, ou seja, quando uma apresenta crescimento a outra também apresenta crescimento, e vice-versa. Para Huntington (1975), a relação é negativa, ou seja, quando uma apresenta crescimento, a outra decresce. No caso de Lipset $(1959,1967)$, a modernização pode ser mensurada por indicadores sociais e econômicos e o desenvolvimento político por democracia ou por sua ausência. No caso de Huntington (1975), modernização pode ser mensurada pelos mesmos indicadores sociológicos e desenvolvimento político pode ser mensurado pelo nível da instabilidade política, ou seja, pelo grau de institucionalização da participação eleitoral e de estruturação dos partidos políticos.

Essa perspectiva de análise, segundo Remmer (1997, 46-7) apresenta a seguinte especificidade: "(...) in terms of the specification of key variables and direction of causality, modernization provided a common point of theoretical departure. Politics, whether defined in terms of individual behavior, institutions, or broad sets of regimes outcomes, was analyzed as dependent variable - a reflection of modernization process, societal values, class structure, or international economic forces, which in turn were defined as exogenous to the political system". De certa forma, esta observação é verdadeira. Lipset $(1959,1967)$ apresenta uma relação causal entre modernização e desenvolvimento político, na qual esta última aparece como variável dependente. Huntington (1975) 
também apresenta uma relação causal entre modernização e desenvolvimento político, mudando apenas o sinal da dependência.

Uma questão que logo se impõe é que um dos dois - ou, talvez, ambos - deve estar equivocado. Apesar de subsidiarem suas conjecturas com dados e, a partir deles, deduzirem como confirmadas suas hipóteses, o mero fato de as duas serem incongruentes conduz à necessária repetição da análise em termos empíricos. Quanto a isso, já foi destacado anteriormente que essas talvez sejam duas das hipóteses mais testadas, contestadas e confirmadas na Sociologia e na Ciência Política. Neste tópico, discutirei algumas análises que refizeram os caminho traçados por aquelas hipóteses e as colocaram, sob novos e diferentes critérios metodológicos, em confronto com dados quantitativos.

No caso de Huntington (1975), pelo fato de sua hipótese não ser tão simpática em relação à promoção da democracia via industrialização, não houve muitas tentativas de revitalização de suas premissas. Contudo, no caso de Lipset $(1959,1967)$, em que há uma relação positiva entre as duas variáveis, a polêmica foi e tem sido bem maior, incentivando uma variedade de pesquisas que focalizaram essa relação. Burkhart \& Lewis-Beck $(1994,903)$ destacam esse aspecto e ressaltam que, devido às influências das hipóteses lipsetianas, em diversas análises, "economic development constently emerges as statistically and substantivelly significant influences on democracy". Por outro lado, Remmer $(1997,34)$ pondera que a literatura que trata da modernização e do desenvolvimento político é "(...) a literature notable less for the rigor of its theoretical specifications or the robustness of its research findings than for the proliferation of abstract, complex, and valueladen concepts". Afinal, qual a consistência analítica $e$ a validade empírica das hipóteses formuladas por Lipset $(1959,1967)$ e Huntington (1975)? Podemos encontrar, de fato, surgimento de democracia ou estabilidade democrática na medida em que aumenta o grau de desenvolvimento econômico? Ou, pelo contrário, podemos observar aumento da instabilidade política em correlação com o processo de modernização?

Com relação à hipótese de Huntington (1975), é possível testar o núcleo central de seu argumento concentrando o foco analítico na participação política - uma vez que a modernização tem como uma de suas características fundamentais a intensificação da participação eleitoral, e que esta seria a componente mais elementar da radicaliza- 
ção política e da instabilidade do sistema. Esse foi o procedimento adotado por Przeworski (1975), que procurou testar empiricamente as deduções extraídas da hipótese huntingtonianas. O estudo foi desenhado de forma a analisar se a entrada de novos eleitores, ou seja, o crescimento da participação, produziria instabilidade política. A lógica é a de que, se estiver correta a hipótese de Huntington (1975), os novos eleitores mobilizados terão expectativas excessivas e diferenciadas em relação aos eleitores já mobilizados há algum tempo. Os eleitores já mobilizados estariam devidamente socializados politicamente, com preferências estruturadas. Os novos eleitores estariam ainda psicológica $e$ sociologicamente atados ao "hiato" existente entre o tradicional e o moderno, carecendo de ordenamento institucional e de agregação de suas demandas. Com isso, a dedução é a de que a mobilização desses eleitores deveria introduzir instabilidade no sistema político.

A proposta analítica de Przeworski (1975) toma os votos como unidade de análise, buscando apreender a diferença agregada nas votações entre duas eleições consecutivas, ponderadas pelos eleitores já existentes no sistema. O autor concluiu que a mobilização não provoca instabilidade no padrão de comportamento eleitoral. As preferências agregadas não sofreram substancial alteração nos períodos de absorção de novos eleitores ao sistema político. Na verdade, segundo Przeworski (ibid., 67), um fator de instabilidade era a desmobilização política. De acordo com o autor, "the threat to the stability of democratic capitalist system comes not from political participation, which for most people involves little more than voting at regular intervals. Rather, the real threat is posed by withdrawls of groups from the electoral process and a loss of legitimacy of the institutionalized forms of conflict processing". Portanto, o ponto central da análise que o autor faz a partir dos dados que refutaram a hipótese huntingtoniana estabelecia que a mera participação em eleições contribuía para a legitimação do processo democrático e que também contribuía, acima de tudo, para a desradicalização do conflito, uma vez que era criada, assim, uma forma institucionalizada de disputa em relação aos recursos escassos a serem distribuídos pelo Estado. ${ }^{6}$

6 Além disso, como o próprio Przeworski (1991) mostrou em outro trabalho, a decisão de participar do jogo eleitoral levou até mesmo os partidos mais radicais à moderação. 
No caso de Lipset $(1959,1967)$, como já enfatizado, a polêmica instalada em torno de sua hipótese é maior, especialmente pela relevância do problema político proposto pelo autor. Diamond (1992, 450) enfatiza esse aspecto e salienta que "asserting a broad and multistranded relationship between economic development levels and democracy, it broke new ground in what come to be known as modernization theory and became an essential reference point, typically the starting point for all future work or the relationship between political system and the level of economic development". Devido a essas características e apesar das críticas que Diamond $(1992,485)$ apresenta ao trabalho de Lipset (1959) - quase todas de caráter metodológico - ele valida sua hipótese, afirmando que "(...) Lipset was broadly correct both in his assertion of a strong causal relationship between economic development promotes democracy and in his explanations of why development promotes democracy". Para chegar a tal conclusão, Diamond (1992) apresenta uma análise muito mais sofisticada em termos estatísticos e, justamente por isso, julga ter reunido elementos consistentes para a validação daquela hipótese. ${ }^{7}$ Seguindo a mesma linha, outros analistas também validaram a hipótese lipsetiana. ${ }^{8}$

Por outro lado, há analistas que apresentaram dados que refutam a conjectura lipsetiana. Nesse caso, é possivel citar alguns trabalhados importantes, tanto do ponto de vista conceitual, quanto do ponto de vista metodológico. Burkhart \& Lewis-Beck (1994) é um exemplo importante desse procedimento. Esses autores criticam a abordagem de Lipset $(1959,1967)$ salientando deficiências metodológicas graves, como o fato de suas amostras serem muito pequenas e por estas, algu-

7 Esses elementos são os seguintes: a) o desenvolvimento sócio-econômico promove democracia mantendo-a onde ela já existe, impondo legitimidade e estabilida$\mathrm{de}$; b) o desenvolvimento sócio-econômico promove democracia onde ela não existe, induzindo, posteriormente, a sua estabilidade; c) o desenvolvimento sócio-econômico induz à quebra do autoritarismo. Contudo, segundo o autor, haveria uma condição necessária à efetividade dessas relações; o desenvolvimento sócio-econômico deveria promover mudanças estruturais em quatro esferas, quais sejam: cultura política (cívica), estrutura de classes (pluralização), relações entre sociedade e Estado (accountability) e fortalecimento da sociedade civil (organização).

8 Esse é o caso de Brunk, Caldeira \& Lewis-Beck (1987), por exemplo, que constataram, em uma análise multivariada, que o desenvolvimento econômico era a única variável que maior peso tem na variação da democracia, em comparação a outras variáveis independentes consideradas conjuntamente. 
mas vezes, não serem nem mesmo representativas. ${ }^{9}$ Segundo esses autores, outros estudos são metodologicamente mais consistentes, como os de Arat (1988) e de Gonick \& Rosh (1988). Arat (1988) utiliza grandes amostras e séries temporais maiores e sua conclusão não valida totalmente a hipótese de Lipset $(1959,1967)$. Segundo ele, "only a few countries fit the models suggested by modernization theory. It could be concluded that increasing levels of economic development do not necessary lead to higher levels of democracy, even for the less developed countries" (Arat: 1988, 30). No caso de Gonick \& Rosh $(1988,196)$, a hipótese foi totalmente negada, uma vez que, de acordo com os autores, "(the) application has allowed us to reject the findings of Lipset".

Ainda no campo da negação das hipóteses do desenvolvimento político, surgiram recentemente dois trabalhos cruciais no que se refere à agregação de dados e ao seu tratamento econométrico (Przeworski \& Limongi: 1997; Przeworski, Alvarez, Cheib \& Limongi: 2000). Przeworski \& Limongi (1998) testaram as hipóteses dividindo-as em dois tipos de explicação. Uma, seria endógena e estabeleceria que a democracia tem maior probabilidade de surgir na medida em que há desenvolvimento sócio-econômico. Outra, seria exógena, e estabeleceria que a democracia tem maior probabilidade de sobrevivência em países desenvolvidos. Pela análise dos dados referentes a vários países, em uma série temporal significativa, os autores confirmaram a hipótese exógena, ou seja, em países com alta renda per capita é muito baixa a incidência de ruptura do regime democrático. Por outro lado, os autores negaram a hipótese endógena.

Em um trabalho mais recente, Przeworski, Alvarez, Cheib \& Limongi (2000) apresentam uma análise com maior profundidade, procurando enfocar vários aspectos da relação entre desenvolvimento econômico e democracia. Os autores constataram que de fato há maior freqüência de democracias em países desenvolvidos e de ditaduras em países não desenvolvidos. Contudo, segundo eles, “(...) wealthy coun-

9 Entretanto, a própria análise crítica de Burkhart \& Lewis-Beck (1994), apesar de oferecer elementos para a refutação da hipótese de Lipset (1959), introduz uma ponderação que leva a uma certa revitalização de suas proposições. De acordo com os autores, "(...) it is clear that economic development substantially improves a nation's democratic prospects. However, the full magnitude of that effect remains statistically and substantivelly significant. Thus, around the world, economic development works to foster democracy" (ibid., 907). 
tries tend to be democratic not because democracies emerges as a consequence of economic development under dictatorships but because, however they emerge, democracies are much more likely to survive in affluent societies" (ibid., 137). Além disso, embora salientem que os dados analisados não sejam conclusivos a respeito do por quê da emergência de democracias e do colapso de ditaduras, não é possível afirmar a existência de "any thresholds of development that would make the emergence of democracy predictable. In sum, modernization theory appears to have little, if any, explanatory power" (ibid.). ${ }^{10}$

Desse modo, esses estudos mais recentes a respeito do tema apresentam como conclusão a afirmação de que a emergência da democracia depende muito mais das decisões dos atores políticos do que de variáveis estruturais, e que, portanto, a democracia pode surgir em qualquer estágio do desenvolvimento econômico. ${ }^{11}$ Entretanto, é possível observar que tais conclusões suscitam questões fundamentais $e$ para as quais os autores não oferecem respostas. Afinal, quais seriam os atores políticos aptos a decidirem pela democracia? Seriam atores homogêneos? Por que decidiriam em determinado ponto e não em outro adotarem a democracia?

Desse modo, ao não apresentarem respostas plausíveis e logicamente coerentes a essas questões, a explicação final conduz a um tipo de solução voluntarista. Talvez, o maior problema das análises de Przeworski \& Limongi (1997) e Przeworski, Alvares, Cheib \& Limongi (2000) seja mesmo o fato de elas serem essencialmente negativas, incorrendo em conseqüências teóricas que os autores procuraram evitar. Ou seja, de fato, elas contestam de maneira contundente a relação causal entre democracia e desenvolvimento sócio-econômico; contudo, deixam um vácuo explicativo, qual seja: o que explica o surgimento da democra-

10 No que se refere à explicação exógena brevemente analisada no artigo anterior (Przeworski \& Limongi: 1997), Przeworski, Alvarez, Cheib \& Limongi (2000) reafirmam sua validade, indicando que a sobrevivência da democracia é bastante previsível e seu melhor preditor é a renda per capita. Sobre isso, os autores introduzem inclusive uma consideração de natureza institucional, observando que a probabilidade de sobrevivência de uma democracia também é mais elevada em regimes parlamentaristas.

11 Outro aspecto importante ressaltado pelos autores é que, uma vez que a democracia seja instaurada, ela terá mais possibilidades de sobrevivência na medida em que o país for mais rico. 
cia? Em sendo decisão dos atores políticos, conforme sugerem esses analistas, há que se explicar os mecanismos que levam à tomada de decisão das elites em favor da democracia, senão nos restará mais uma vez a concepção culturalista de que as elites políticas latino-americanas poderiam decidir pela democracia, mas não o fazem porque não possuiriam uma cultura cívica favorável à existência desse tipo de regime político.

Na verdade, qualquer resposta que nega as variáveis estruturais como sendo independentes na relação com a democracia, quase sempre incorre em outro problema que é o de deixar aberta a porta de sua teoria para a entrada de explicações culturalistas. Afinal, se os críticos da teoria da modernização fincam seu mastro teórico no campo do institucionalismo racionalista (rational choice institutionalism), é certo que partem da premissa de que os atores, todos eles, independente da época histórica e do contexto cultural, são racionais. Se assim o for, então, por que alguns atores, em alguns países, em algumas épocas históricas específicas, decidem pela democracia e outros não o fazem? Ou alguns atores são irracionais, e, então, o modelo teórico se mostra inócuo, ou existiriam variáveis culturais que explicariam essas variações, e, nesse caso, a premissa da racionalidade não possui qualquer valor explicativo e a conjectura do desenvolvimento político mantém válida parte de suas premissas. Esse é o problema teórico e, de certa maneira, lógico, que as análises refutadoras da teoria da modernização têm de lidar, como passo de maior maturidade analítica a ser dado depois da consistente negação das hipóteses de Lipset $(1959,1967)$ e Huntington (1975).

\section{Conclusão}

Dois objetivos motivaram a discussão que desenvolvi neste texto. O primeiro foi procurar ressaltar as características principais das argumentações de Lipset $(1959,1967)$ e Huntington (1975) a respeito da relação entre desenvolvimento político e modernização. Para tanto, as hipóteses concorrentes desses autores foram tomadas como eixo da exposição, de forma que fosse possível mostrar divergências e convergências em suas análises e em suas proposições. Dessa maneira, julgo ter demarcado analiticamente qual a tese principal que os coloca em 
pólos opostos no que se refere à concepção de qual seria o melhor meio de promover o desenvolvimento político.

Meu segundo objetivo foi tentar ressaltar a importância desses autores no campo da análise de política comparada. Nesse caso, minha intenção foi evidenciar o quanto essa teoria, equivocada ou não, contribuiu para incrementar o debate na Ciência Política desde os anos 60 até a atualidade. Conforme procurei mostrar, por meio do confronto da teoria da modernização com análises mais recentes, as convergências e divergências entre esses autores se constituíram em torno de hipóteses que já foram, várias vezes, submetidas ao teste popperiano da falsificação, desencadearam toda uma linha de pesquisa comparativa que se mantém até hoje em atividade, geraram herdeiros e críticos, movimentaram e movimentam parte da produção acadêmica contemporânea nessa área.

De certa maneira, e acima de tudo, minha intenção foi evidenciar que a vitalidade da teoria do desenvolvimento político se explica pelo inegável fato de que esta se configurou como uma autêntica teoria científica, de acordo com os critérios popperianos. Isso porque suas proposições apresentam orientação empírica, com elevados graus de "testabilidade", ou seja, com enunciados passíveis de falsificação. Assim, uma teoria que surgiu submersa em concepções verificacionistas, repleta de generalizações indutivistas, ao longo do tempo, foi-se submetendo a uma espécie de reenquadramento epistemológico, em que novos pesquisadores a tomaram como teoria a ser testada - portanto, dedutiva - em casos singulares. As relações entre variáveis políticas, sociais e econômicas tornaram possível não apenas a quantificação e a conseqüente mensuração dos fenômenos, como também, por isso mesmo, possibilitaram a sucessiva realização de testes "cruciais".

Devido a esses aspectos, as discussões suscitadas pela teoria da modernização ou, como sugeri neste texto, da conjectura do desenvolvimento político, permanecem na agenda de pesquisa de vários politólogos, e justamente por isso ainda são analisadas as relações entre Economia e Política, entre democracia e capitalismo, entre instituições e atores e entre cultura e democracia. As maiores controvérsias existentes atualmente e que permitem a sobrevivência dessa teoria, a despeito de suas sucessivas falsificações, residem atualmente em questões de ordem técnica. As constantes confirmações de suas hipóteses e suas posteriores negações variam em função do tamanho da amostra dos 
casos selecionados e, fundamentalmente, em função das sofisticações dos instrumentais matemáticos e estatísticos que têm possibilitado os mais variados testes empíricos e o próprio avanço metodológico da Ciência Política em todo o mundo.

\section{Referências bilbiográficas}

Almond, G; Powell JR., G. Uma teoria de política comparada. Rio de Janeiro: Zahar, 1980.

ARAT, F. Democracy and economic development: modernization theory revisited. Comparative Politics, n. 21, 1988.

Burkhart, Ross; LewIS-BeCK, Michael. Comparative democracy: the economic development thesis. The American Political Science Review, v. 88, n. 4, 1994.

Brunk, G.; Caldeira, G.; Lewis-Beck, M. Capitalism, socialism, and democracy: an empirical inquiry. European Journal of Political Research, n. 15, 1987.

CHILCOTE, Ronald. Teorias de política comparativa. Rio de Janeiro: Vozes, 1998.

DiAmond, Larry. Economic development and democracy reconsidered. American Behavioral Scientist, v. 35, n. 4/5, 1992.

ECKSTEIN, Harry. A culturalist theory of political change. The American Political Science Review, v. 82, n. 3, 1988.

GonICK, L.; Ross, R. The structural constraints of the world-economy on national political development. Comparative Politics Studies, n. 21, 1988.

HAGGARD, Stephan. Pathways from the periphery. Ithaca: Cornell University Press, s/d.

Huntington, Samuel. A ordem politica nas sociedades em mudança. São Paulo: Forense, 1975.

. One soul at a time: political science and political reform. The American Political Science Review, v. 82, n. 1, 1988.

.; Nelson, Joan. No easy choice: political participation in developing countries. Harvard University Press, s/d.

LIPSET, S. Some social requisites of democracy: economic development and political legitimacy. The American Political Science Review, v. 53, n. 1, 1959.

O homem político. Rio de Janeiro: Zahar, 1967.

PrzeWORSKI, Adam. Institutionalization of voting patterns. The American Political Science Review, v. 69, 1975. 
. Capitalismo e social-democracia. São Paulo: Cia. das Letras, 1991.

.; LIMONGI, F. Modernization: theories and facts. World Politics, n. 49, 1997.

.; Alvares, M.; Cheib, J.; Limongi, F. Democracy and development. Cambridge University Press, 2000.

REMMER, Karen. Theoretical decay and theoretical development: the resurgence of institutional analysis. World Politics, v. 50, n. 1, 1997.

SARTORI, Giovanni. Political development and political engineering. In: Montgomery, John; Hirshman, Albert (Eds.). Public policy. Harvard University Press, 1968.

. Partidos e sistemas partidários. Rio de Janeiro: Zahar, 1982. 